\title{
Changing research methodology: Two case studies of critical realism informing social work doctoral research
}

Shajimon Peter and Lynne Soon-Chean Park University of Auckland, New Zealand

\begin{abstract}
INTRODUCTION: Critical realism (CR) has much to offer to social work research because of its recognition of the existence of objective and subjective realities. Bhaskar (1978) classifies these levels of reality as the empirical, the actual and the real. Empirical realities emerge from our experience of the world and include our subjective constructions. The underlying real reality is seen as a productive force, causing the empirical to appear. Researchers using CR methodology can employ an analytic process called retroduction. This approach involves moving back and forth from the empirical to the real to identify causal mechanisms that drive the empirical to manifest.
\end{abstract}

\begin{abstract}
APPROACH: This research brief is the outcome of a research methodology literature review undertaken by two doctoral students who employ CR perspectives. Their research proposals have been used as case studies to demonstrate the usefulness of $C R$ in informing social work research. These findings were presented at the ANZSWWER international symposium held at the University of Auckland in New Zealand.
\end{abstract}

FINDINGS: CR uncovers the epistemic fallacy of reducing ontology to the realm of epistemology. The totalising truth claims of both objectivism and subjectivism are replaced with an alternative conception of stratified forms of reality - the real, actual and empirical. Reality exists both objectively and subjectively. This enables researchers to bridge social constructionism and structural causation. It allows for study that explores the subjective considerations of respondents while examining the objective existence of causal mechanisms such as social structures, systems or processes.

CONCLUSION: CR offers an alternative that social work researchers have long been searching for: to engage meaningfully in studies that examine perceived realities at the empirical level and the causal mechanisms that lie behind them.

KEYWORDS: Critical realism; research methodology; social work research

\section{Introduction}

Social work researchers have long been constrained by an ontological binary - by the lack of a methodological approach that allows them to engage in research without aligning it to either an objectivist or a subjectivist stance. Although social work is interested in what matters to people and how and why certain things matter to people (Houston, 2001; Sayer, 2011), both positivist and constructivist perspectives fail to truly engage in the
AOTEAROA

NEW ZEALAND SOCIAL WORK 30(1), 65-70.

CORRESPONDENCE TO: Shajimon Peter speter@eit.ac.nz 
complex interplay between "fact and value, between the is and the ought, between the positive and the normative" [original emphasis] (Longhofer \& Floersch, 2012, p. 501). Critical realism offers a means of moving from "surface" to "depth" in social work practice and for developing empirically based theory about why certain empirical events arise from intervention in a specific social situation (Houston, 2001, p. 853).

CR, as proposed by Bhaskar $(1978,1979$, $1989,1998)$, proposes that both positivism (objectivism) and constructivism (subjectivism) are both subject to what is termed the epistemic fallacy: that the nature of reality is reduced to human knowledge (Bhaskar, 1998, p. 27). Positivism acknowledges the existence of a real world that exists independently of our beliefs and constructions. However, the nature of reality is reduced to what can be empirically investigated through scientific experiments. On the contrary, constructivism denies the objective existence of reality and regards reality as entirely constructed through and within human knowledge or discourse. This approach also reduces reality to our knowledge of reality. As Bhaskar (1998) identifies, the problematic reduction of ontology to epistemology happens in both approaches. CR posits that one can only ever attempt to come closer to the real reality and not capture it fully.

CR presents reality as stratified into three levels, or "ontological domains" (see Bhaskar, 1978, p. 56). The surface level is empirical reality which we can experience and observe. Thus, empirical reality is mediated through the lens of human experience and interpretation. The middle level is actual reality where no filter of human experience exists and hence events happen whether we experience them or not. The third level is the real level of reality that consists of the causal forces which produce events at the empirical level. In CR ontology, the real level of reality is a central concept. The primary goal of CR is "to explain social events through reference to these causal mechanisms and the effects they can have throughout the three layers of reality" (Fletcher, 2017, p. 183).
This schema potentially raises an epistemological question as to how the real level of reality can be identified. Bhaskar (1979) argues that, unlike the natural world, social worlds are social products that can only manifest through social events or phenomena. The causal mechanisms in the social world "exist only in virtue of the activities they govern and cannot be empirically identified independently of them" (p. 48). It follows that causal mechanisms can be explained ultimately through phenomena at the empirical level. However, the social world is a dynamic and unpredictable open world in which potentialities inherent in causal mechanisms enable or constrain it from acting in certain ways (Bhaskar, 1979). Accordingly, in CR research, researchers engage in a retroductive reasoning process to identify certain social conditions for the actualisation of causal mechanisms in a real level of reality (Bhaskar, 1979).

What is most useful about CR for social work is its recognition of generative mechanisms that cause specific observable phenomena to manifest and the possibility of making changes to those mechanisms that could lead to the manifestation of different phenomena. For example, if some unjust social structures or systems cause undesirable emergent social practices, identifying and changing those structures and systems could lead to the manifestation of more desirable outcomes. In the example of Case Study One in the next section, it would mean examining the structures, systems or processes that impede or promote effective transition of transnational social workers into New Zealand and, in Case Study Two, it would mean identifying the causal mechanism in the settlement process and its impact on the perceived and practised meaning of trust among Korean-ethnic migrants in the context of New Zealand.

The following is a discussion of two doctoral research proposals that are taken as case studies to illustrate the usefulness and significance of CR in informing social work research. Both studies are being pursued at the University of Auckland and conducted in the New Zealand context. 


\section{Case Study One:}

\section{The Project}

Case study one refers to a doctoral research proposal that examines the strategies and mechanisms in place in receiving countries to facilitate the transition of transnational social workers. A transnational social worker is defined as a "professional who undertakes professional practice in any other country than her home country or the one in which she received her training and qualifications" (Peter, Bartley, \& Beddoe, 2017, p. 2). Their unassisted transition can engender unintentional harm to both the transnational social workers themselves and to their service users. However, a profession-wide response to this potential problem is not reported to date in social work, although other professions such as nursing and teaching do have some form of profession-wide responses (Peter et al., 2017).

The study explores the perspectives of stakeholders and considers causal mechanisms such as structures, systems or processes that impede or promote transition. This lends itself well to a theory that recognises the existence of an objective reality (the influence of social structures irrespective of what people perceive them to be) and which also acknowledges people's subjective construction of their own reality. CR recognises individual meaning-making and its correspondence to an external reality. According to Houston (2010) critical realism perceives social structures as having "durable enduring patterns of behaviour, social rules, norms and law-like configurations" (p. 75) that have real effects on the lives of people. Bhaskar (1989) points out that "we will only be able to understand and so change - the social world if we identify the structures at work that generate those events and discourses ... These structures are not spontaneously apparent in the observable pattern of events; they can only be identified through the practical and theoretical work of the social sciences" (p. 2).

\section{Case Study One:}

\section{Methodology}

A major criticism of CR is that it does not offer a clear research methodology or data collection methods. Some have pointed out that CR "is not aligned with or easy to translate into a given methodology" (Craig \& Bigby, 2015). However, CR has been applied in qualitative research (see Fletcher, 2017) and with a grounded theory approach (see Craig \& Bigby, 2015). Yet another approach used by researchers is combining CR with pragmatism, a compatible philosophical position (see Johnson \& Duberley, 2000). The present study uses a qualitative strategy and insights from a pragmatic theoretical perspective are utilised to explain methodological positioning:

Being pragmatic allows one to eschew methodological orthodoxy in favour of methodological appropriateness [emphasis in original] as the primary criterion for judging methodological quality, recognizing that different methods are appropriate for different situations. (Patton, 2002, p. 72)

Linking a CR view with the pragmatic approach, Johnson and Duberley (2000) suggest that a pragmatic view of truth "challenges any quest for certainty" and acknowledges its fallibilistic nature as "any knowledge claims, at any given time, may be wrong and all beliefs are thus revisable" (Johnson \& Duberley, 2000, p. 14).

According to critical realism, the social world (unlike the natural world) is "an outcome of human action and therefore there is always the potential for changing existing relationships through action. If social reality consists of causal structures it must be possible to intervene and manipulate that structure [sic]" (Johnson \& Duberley 2000, p. 16). In the context of the proposed research, this allows for the possibility of identifying and acting upon social structures in a way that may promote or impede transitional assistance to transnational social workers (TSWs). 


\section{Case Study One:}

\section{Empirical data \& analysis}

Focus groups with stakeholders (TSWs and employers of TSWs) will be used for data collection. Data analysis in CR can be conceptualised as a process of coding, abduction and retroduction. Coding is the process of identifying demi-regularities (see Fletcher, 2017) in the observable empirical realm of reality. At this stage, researchers look for patterns or tendencies (see Danermark, Ekstrom, Jacobsen, \& Karlsson, 2002) that can be listed as codes. Abduction is the second step after coding of the empirical data has been completed. Abduction is a process which is also known as theoretical re-description "in which empirical data are re-described using theoretical concepts" (Fletcher, 2017, p. 188). Theories on new migration trends such as transmigration will be applied in the process of abductive reasoning. The transitory nature of migration and how that impacts on service provision will be examined (see Peter, 2017). Danermark et al. (2002) define abductive reasoning as "inference or thought operation, implying that a particular phenomenon or event is interpreted from a set of general ideas or concepts" (p. 205). As Fletcher (2017) points out, "Abduction raises the level of theoretical engagement beyond thick description of the empirical entities, but with an acknowledgement that the chosen theory is fallible" (p. 188).

Retroduction is the final stage of CR analysis in which the researcher attempts to identify causal mechanisms and conditions that drive the manifestation of empirical reality.

The goal of retroduction is to identify the necessary contextual conditions for a particular causal mechanism to take effect and to result in the empirical trends observed. (Fletcher, 2017, p. 189)

Bryman (2012) defines retroduction as "a form of reasoning that entails making an inference about the causal mechanism that lies behind and is responsible for regularities that are observed in the social world" (p. 715). At the retroduction stage, researchers engage in a reasoning process that moves from "the manifest phenomena of social life, as conceptualised in the experience of the social agents concerned, to the essential relations that necessitate them" (Bhaskar, 1979, p. 32). It is this aspect of CR that makes it critical. According to Bryman (2012), this is because "the identification of generative mechanisms offers the prospect of introducing changes that can transform the status quo" (p. 29).

\section{Case Study Two:}

\section{The project}

Case study two refers to a doctoral research project that aims to explore the social and cultural effects of migration as it relates to conceptualising the notion of trust. Even though trust is a universal phenomenon, the way in which people conceptualise and utilise trust is culturally constrained (Doney, Cannon, \& Mullen, 1998). The concept of trust has been a focus of the migration research community as one of the indicators of social capital in affecting migrants' life satisfaction (Helliwell \& Wang, 2010; Laczko \& Appave, 2013; Wagner, 2014). However, there has been little discussion of how trust is conceptualised and utilised by migrants during their transitional process in their host country. This study examines the impact of the settlement process and the effect it has on the conceptualisation of the meaning of trust and explores how Korean migrants perceive and practise trust during their transitional process in Aotearoa New Zealand.

This research requires a perspective that acknowledges the existence of an objective reality (the influence of social structures or processes regardless of the way people perceive or experience them) while also recognising the presence of a subjective reality constructed through human knowledge or discourse. A CR approach enables insight into both the way that people interpret and give meaning to 
their experience and how this perception corresponds to enabling and/or constraining the effects of objective social structures (Houston, 2010). To provide a more detailed explanation of the process involved in conducting $\mathrm{CR}$ research, the present study follows the methodological guidelines suggested by Fletcher (2017). The following section explains the planned process of the applied CR analysis.

\section{Caste Study Two:}

\section{Process of applied CR analysis}

Research inquiry adopted by existing theories. As a starting point, CR research begins with an inquiry that has been guided by existing theories. The present research inquiry is prompted by existing research in which four trust constructs such as trust, trustworthiness of beliefs, propensity to trust, and trusting behaviour are adopted to inform the influence of society and culture on the conceptualisation of the construct of trust (Dietz, Gillespie, \& Chao, 2010). However, in keeping with CR epistemology, the initial theories can be supported, modified, or even rejected through a deeper $\mathrm{CR}$ analytical process, since the existing theories "can be more or less truth like" (Danermark et al., 2002, p. 10).

Data collection using extensive and intensive data. Social phenomena are observed or experienced at the empirical level of reality (Bhaskar, 1979) and the related data can be collected from two major sources: (a) data that show widespread trends, for example, statistical data; and (b) interpretive in-depth data from in-depth interviews or focus group discussions (Fletcher, 2017). For this study, extensive data is drawn from an internationally based trust survey and a domestic Korean study to identify certain tendencies. The intensive data collection source is comprised of 30 in-depth individual interviews and is followed up with five focus group interviews with three different generations of Korean migrants.
Data coding process of searching for demi-regularities. The cycles of the coding process follow a deductive and flexible theory "directed" coding process (Hsieh \& Shannon, 2005, p. 1281). The data coding process for the current study is guided by provisional codes that draw upon the literature review and essential CR concepts. As described by Maxwell (2012), provisional codes consist of topic-based codes and prior theory-based codes. The coding phase of the present study consists of the re-organisation and integration of the codes into a CRinformed conceptual map that includes social structure and human agency. Throughout these coding cycles, the most prominent codes are used as a foundation to identify the demi-regularities of the empirical data.

Data analysis through abduction and retroduction. After identifying the tendencies of the data, a process of abductive reasoning follows to identify the social processes by engaging with the existing theories (Fletcher, 2017). Then Houston's (2010) domains of social life are applied to identify the mechanisms operating within the domains and how they interact with one another. This abductive reasoning aims to classify the causal mechanisms that go beyond the individual sphere and that influence the empirical phenomena in certain ways. The final stage of CR analysis aims to ascertain the context for the causal mechanism to take effect and to result in the tendencies observed from the empirical data. To identify the necessary contextual conditions, a retroductive reasoning process is applied by constantly moving between the empirical levels and the deeper levels of reality (Lawson, 1998). Houston's model (2010) is applied again to identify the specific context of the actualisation of the causal mechanism as it relates to the social structures.

\section{Conclusion}

The alternative theoretical perspective that CR offers to positivism and constructivism is potentially beneficial to researchers engaging 
in studies that examine structural problems and conditions that lie beneath the surface level of observable phenomena. The stratified levels of reality that CR puts forth allows researchers to design a study using qualitative strategies to investigate both objective and subjective realities. This, however, is a decision that researchers make discretionally in the absence of any specific methodology that can be identified with CR. The fact that the form of reasoning involved in CR is neither inductive nor deductive allows researchers to use retroductive reasoning while examining objective and subjective realities within a qualitative framework. This is particularly significant for social work researchers as it allows for the introduction of changes that can alter existing states of affairs. The two case studies of social work doctoral research proposals presented in this paper highlight some of the exciting possibilities CR offers to qualitative researchers.

\section{References:}

Bhaskar, R. (1978). A realist theory of science. Hassocks, UK: Harvester Press.

Bhaskar, R. (1979). The possibility of naturalism: A philosophical critique of the contemporary human sciences. Atlantic Highlands, NJ: Humanities Press.

Bhaskar, R. (1989). Reclaiming reality: A critical introduction to contemporary philosophy. London, UK: Verso.

Bhaskar, R. (1998). Philosophy and scientific realism. In M. Archer, R. Bhaskar, A. Collier, T. Lawson, \& A. Norrie (Eds.), Critical realism: Essential readings (pp. 16-47) Routledge.

Bryman, A. (2012). Social research methods (4th ed.). New York, NY: Oxford University Press.

Craig, D., \& Bigby, C. (2015). Critical realism in social work research: Examining participation of people with intellectual disability. Australian Social Work, 68(3), 309-323. doi:10.1080/0312407X.2015.102426

Danermark, B., Ekstrom, M., Jakobsen, L., \& Karlsson, J. C. (2002). Explaining society: An introduction to critical realism in the social sciences. New York, NY: Routledge.

Dietz, G., Gillespie, N., \& Chao, G. T. (2010). Unravelling the complexities of trust and culture. In M. N. K. Saunders, D. Skinner, G. Diets, N. Gillespie, \& R. J. lewicki (Eds.), Organizational trust: A cultural perspective (pp. 3-41). Cambridge, UK: Cambridge University.

Doney, P.M., Cannon, J.P., \& Mullen, M.R. (1998). Understanding the influence of national culture on the development of trust. Academy of Management Review, 23(3), 601-620.

Fletcher, A. J. (2017). Applying critical realism in qualitative research: Methodology meets method. International Journal of Social Research Methodology, 20(2), 181-194.
Helliwell, J. F., \& Wang, S. (2010). Trust and well-being (NBER working paper No. 15911). Cambridge, UK: National Bureau of Economic Research.

Houston, S. (2001). Beyond social constructionism: Critical realism and social work. British Journal of Social Work, 31(6), 845-861. doi:10.1093/bjsw/31.6.845

Houston, S. (2005). Philosophy, theory and method in social work: Challenging empiricism's claim on evidence-based practice.Journal of Social Work, 5(1), 7-20.

Houston, S. (2010). Prising open the black box: Critical realism, action research and social work. Qualitative Social Work, 9(1), 73-91. doi:10.1177/1473325009355622

Hsieh, H., \& Shannon, S. E. (2005). Three approaches to qualitative content analysis. Qualitative Health Research., 15(9), 1277-1288. doi:10.1177/1049732305276687

Johnson, P., \& Duberley, J. (2000). Pragmatism and critical realism - Transcending Descarte's either/or? In P. Johnson \& J. Duberley (Eds.), Understanding management research: An introduction to epistemology. London, UK: Sage Publications Retrieved from http://methods.sagepub.com/book/understandingmanagement-research

Laczko, F., \& Appave, G. (2013). World migration report 2013: Migrant well-being and development. Geneva, Switzerland: International Organization for Migration.

Lawson, T. (1998). Economic science without experimentation. In M. Archer, R. Bhaskar, A. Collier, T. Lawson, \& A. Norrie (Eds.), Critical realism: Essential readings (pp. 144-186). London, UK: Routledge.

Longhofer, J., \& Floersch, J. (2012). The coming crisis in social work: Some thoughts on social work and science. Research on Social Work Practice, 22(5), 499-519.

Maxwell, J. A. (2012). A realist approach for qualitative research. Thousand Oaks, CA: SAGE.

Patton, M. Q. (2002). Qualitative research and evaluation methods (3rd ed.). Thousand Oaks,CA: Sage Publications.

Peter, S. (2017). Transmigration. [Review of the book Transmigration: Social work in a world of superdiversity by M. Schrooten, S. Withaeckx,D. Geldof, \& M. Lavent, ]. International Journal of Social Welfare, 26, 417-418. http://onlinelibrary.wiley.com/doi/10.1111/ijsw.12286/full

Peter, S., Bartley, A., \& Beddoe, E. (2017). Transnational social workers' transition into receiving countries: What lessons can be learnt from nursing and teaching. European Journal of Social Work. doi:10.1080/ 13691457.2017.1366430.

Sayer, A. (2011). Why things matter to people: Social science, values and ethical life. New York, NY: Cambridge University Press.

Wagner, B. F. (2014, May). Trust: The secret to happiness? Exploring social capital and subjective well-being among immigrants. Paper presented at the 2014 Annual Meeting of the Population Association of America, Boston, MA. Retrieved from http://paa2014.princeton. edu/abstracts/142867 